\title{
GROTOWSKI EM NOVA YORK INVERNO DE 1993
}

\begin{abstract}
Juliusz Tụszka
Desde 1978, trabalha no Instituto de Estudos Culturais. Autor de seis livros e de cerca de 200 artigos, com publicações na Polônia, Bélgica, França, Holanda, lugoslávia, Alemanha, Romênia, EUA e Itália. Membro honorário da Associação Internacional de Teatro para Crianças e Jovens (ASSITEJ), membro da Federação Internacional de Teatro de Pesquisa (FIRT).
\end{abstract}

Tradução: NET/UFRGS

Tradução feita pela Professora Rosalia Neumann Garcia, membro do Núcleo de Estudos de Tradução Professora Olga Fedossejeva NET, Instituto de Letras / UFRGS, em parceria com o aluno de graduação Renato Augusto Vortmann de Barba. 
O texto a seguir é um relato do encontro com Jerzy Grotowski no Teatro Caixa Preta da Escola de Pesquisas Educacionais da Universidade de Nova York, no parque Washington Square em fevereiro de 1993. Este encontro foi o ponto culminante na programação de um seminário dedicado à fase teatral na vida e obra de Grotowski. Foi organizado por Robert Taylor, professor do Departamento de Pesquisas Educacionais, e por Robert Findlay, seu colega da Universidade de Kansas. O autor deste relato acatou a exigência de ambos os organizadores da conferência, bem como do próprio Grotowski, e não gravou o encontro, limitando-se a tomar notas detalhadas em sua língua materna. Como resultado dessas operações, circunstâncias muito problemáticas ocorreram: durante o encontro, a única língua usada era o inglês, enquanto que este texto foi originalmente escrito em polonês. A versão atual do relato é, na verdade, o resultado de uma "dupla tradução". Além disso, depois que Grotowski familiarizou-se com a versão em polonês, ele a aceitou e informou sua decisão ao autor em maio de 1996, quando se encontraram durante a 10 ${ }^{\underline{a}}$ sessão da Escola Internacional de Antropologia Teatral, em Copenhague.

26 de fevereiro de 1993, sexta-feira, 8:30, ainda resta meia hora de espera antes do encontro. O saguão do Teatro Caixa Preta está cheio, de acordo com os desejos dos organizadores. A atmosfera está transbordando de ansiedade.

Eu vejo várias pessoas conhecidas. André Gregory, Margaret Croyden, o professor Daniel Gerould com sua esposa Jadwiga Kosicka, estão todos aqui. Também reconheço Magda Złotowska, que traduziu Uspienski de "Fragmentos de Ensino Desconhecido" para o Polonês.

8:30 - ambos os lados da sala estão cheios, mas não há multidões. No centro, há uma mesa com duas cadeiras, as luzes estão direcionadas para o espaço onde Grotowski irá se sentar em um minuto. Elas são suaves, não muito fortes. 
9:03 - As portas ao fundo da sala se abrem, e por um minuto Grotowski fica lá parado, hesitante, sob a luz. Ele se aproxima da mesa e senta em uma das cadeiras. Ele entrou pela entrada lateral, e irá sair pelas mesmas portas. Ninguém na sala ousa se movimentar, não há aplausos - estas foram as diretrizes que recebemos ontem, e que foram repetidas hoje. Também sabemos o que fazer quando o Mestre decidir que é hora de encerrar o encontro: devemos permanecer em nossos lugares por alguns minutos depois que ele sair. É absolutamente proibido se aproximar de Grotowski e pedir um autógrafo. Findlay e Taylor nos disseram que ele estava muito debilitado após os dois infartos que havia sofrido no ano anterior, e cada contato simplesmente pode ser prejudicial à sua saúde.

Findlay, muito entusiasmado, abre o encontro oficialmente. Ele está nos informando com antecedência, mais uma vez, que nosso convidado tem o direito de encerrar o encontro e partir caso ele sinta que cruzou o limite da fadiga que é permitido em suas condições. Todas essas precauções são justificáveis - o homem que acaba de entrar na sala aparenta fraqueza. Ele está magro (o terno preto cai sobre ele com letargia e impotência como em um espantalho), seus movimentos são lentos e inseguros.

Grotowski começa a falar sobre o filme que vamos ver em um minuto. Ele diz que atualmente alguns "especialistas" estão tentando perpetuar o mito da "espontaneidade" completa dos atores do Teatro Laboratório durante suas apresentações. A prova contrária a essa mentira deslavada pode realmente ser o filme da performance de $O$ Príncipe Constante. O filme foi feito em segredo, e quando foi finalmente revelado a Grotowski, e quando a companhia o aceitou como um documento do seu trabalho, a gravação de som foi realizada (o filme era mudo). A performance completa foi gravada novamente, segundo após segundo, sem cortes e sem edição. E o que se provou com isso? Que as gravações foram feitas dentro de um intervalo de dois anos e o som se encaixava perfeitamente no vídeo! Foi uma atuação extremamente "espontânea". 
Grotowski fala devagar, com esforço. Seu inglês é enrolado, com um sotaque polonês-francês e muitos erros gramaticais. No entanto, ninguém presta atenção nestas imperfeições linguísticas. Com um pouco de esforço, é possível compreender o que ele fala e, pela maneira com que fala, tudo o que ele quer transmitir.

Enquanto isso, nosso convidado conta como alguns outros espectadores de O Príncipe Constante concluíram que a coreografia sofisticada deste show tinha sido o resultado do árduo trabalho criativo de Grotowski e sua companhia. Quando ele Ihes disse que tudo tinha sido desenvolvido de forma espontânea, e que só depois deste ponto todos os detalhes foram modelados, não quiseram acreditar nele. A espontaneidade desta performance existia principalmente na "luz interior" de Ryszard Cieślak. Foi um fenômeno excepcional e inesquecível para Grotowski. Depois de ter trabalhado um ano no seu papel, Cieślak sabia perfeitamente o que deveria fazer e quando deveria fazê-lo, de modo que a cada repetição da performance ele era capaz de se concentrar em seu processo interno. Grotowski, enquanto trabalhou com Cieślak, nunca lhe disse o que fazer. O tema trabalhado foram as memórias da adolescência do ator. Eles realmente só se concentraram em um quarto da vida do Cieślak. Nessa idade, experiências de amor (e foi este o assunto desses quinze minutos) são físicas e relacionam-se com a alma e com Deus. A memória destes minutos os acompanhou durante o trabalho sobre os monólogos de Don Fernando. Cieślak entrou no processo com todo seu corpo. Ele pensou no que vinha fazendo até então. O que ele vinha pensando era irrelevante.

As recordações ocorreram enquanto eles estavam trabalhando, durante uma de suas conversas. Grotowski, como diretor, nunca impôs nada, nunca ditou, mas, sim, dava coragem ao ator. O trabalho que eles compartilhavam era o seu segredo. Quando ensaiavam com o grupo, Cieślak fingia atuar para que ele pudesse em algum momento surpreender os outros atores com o processo. Grotowski e Cieślak se firmaram estritamente pela regra de que não iriam perder tempo falando sobre a vida íntima, e que gostariam de comentar o seu trabalho apenas até onde fosse 
necessário. Mais tarde, ambos se esforçaram para se conter ao falar sobre o trabalho que compartilharam no papel de Don Fernando. Somente após alguns anos, Cieślak decidiu revelar alguns dos fatos para seus alunos. O que Grotowski nos contou hoje é apenas uma repetição do que Cieślak decidiu divulgar. Grotowski jamais irá contar isso novamente a alguém.

Chegou o momento de ver o filme. Quando acabou, de sua cadeira, Jerzy Grotowski se inclinou em nossa direção, olhou atentamente para a audiência e disse que estava esperando por perguntas.

A primeira foi relacionada ao seu trabalho na composição de $O$ Príncipe Constante, e especialmente sobre a forma como os monólogos de Cieślak foram incorporados à estrutura do show. Grotowski primeiro declarou que nem todas as cenas tinham sido montadas em ordem cronológica. Por exemplo, a cena das chicotadas apareceu apenas no final do trabalho. Em seguida, nosso convidado voltou para o tema das criações de Ryszard Cieślak. Os monólogos de Fernando transmitiam as experiências felizes do ator, sua voz era alegre, enquanto que o texto falava de sofrimento e humilhação. O subconsciente do ator trabalhava nas memórias da juventude, enquanto simultaneamente ele interpretava um texto sobre tormento. Isto provou ser enganoso para alguns imitadores, que eram capazes apenas de imitar a crueldade externa dessas cenas.

A edição do diretor foi efetivamente conduzida no terreno da imaginação do espectador. O texto e a situação deveriam evocar associações de sofrimento e crueldade, mas ao mesmo tempo ela foi influenciada pelo processo interno do ator. Portanto, Grotowski e Cieślak provaram que este processo pode ser separado em uma peça de teatro da edição do diretor. Foi um ato de vida no teatro, um ato de extrema honestidade de um ator. Desencadeá-lo era a tarefa de Cieślak, enquanto que a edição era a tarefa de Grotowski. Ele tentou compor cada cena com precisão matemática, para que pudesse evocar no espectador o trabalho específico de imaginação. 
A pergunta seguinte se relacionou ao significado político de $O$ Príncipe Constante. Jerzy Grotowski começou afirmando que este drama é bem conhecido na Polônia. (Eu fiquei um pouco surpreso - talvez tivesse sido bastante conhecido na década de 60, mas ainda seria?). O Mestre então contou a história de $O$ Príncipe Constante de Calderón e Słowacki, apontando para os motivos da prisão, da tortura e da pressão mental que foi colocada sobre o prisioneiro a fim de induzi-lo a cooperar com seus torturadores. Ele acrescentou que atualmente, entre os poloneses, tais eventos ainda evocam associações com o passado não tão distante. Também os trajes dos membros da corte faziam referência direta às roupas dos promotores militares poloneses, que na maioria das vezes haviam conduzido julgamentos políticos na época stalinista.

No entanto, a performance do Teatro Laboratório não era apenas uma acusação do totalitarismo - fosse soviético ou alemão. Feniksana, enquanto decidia a punição de Dom Fernando, recitava ao mesmo tempo uma oração católica - uma das alusões ao fanatismo católico.

Então, alguém pergunta sobre o trabalho de Cieślak no texto. Grotowski responde que ambos basearam-se nos monólogos de Dom Fernando enquanto trabalhavam juntos. O que se seguiu após a familiarização com o texto foi 0 conhecimento aprofundado da estrutura linguística do drama. É só então, durante o trabalho do som em Pontedera, que Grotowski descobriu como estava fascinado pela estrutura acústica pura do texto.

Os monólogos foram decorados. Cieślak, quando acordado no meio da noite, era capaz de recitá-los sem vacilar, a partir de qualquer ponto. Veio então o momento de trabalhar em associações, as quais deveriam ser evocadas na imaginação do ator pelas partes específicas do texto. Como resultado, o texto foi separado do processo interior do ator.

A próxima pergunta foi: $O$ trabalho deles foi baseado em improvisações ou em conversas? Grotowski sorri e diz que esse tipo de trabalho, mesmo quando 
muito intenso, nunca pode depender apenas das reuniões durante os ensaios. Houve ensaios de fato, mas também houve conversas. A fase mais significativa de trabalho começou a partir de uma delas. Ambos estavam sentados em uma mesa no restaurante de uma estação de trem. Grotowski declara para Cieślak que "Algumas experiências da juventude tendem a ser semelhantes para a maioria das pessoas. Como foi para você?" Cieślak decidiu falar. Grotowski ficava perguntando: "O que você estava fazendo, então? O que estava acontecendo com seu corpo? E com a sua respiração?" Cieślak respondia enquanto Grotowski tomava notas. Mais tarde, durante um ensaio, Cieślak simplesmente tentou capturar as ações exatas deste momento em sua juventude. O que ele vinha fazendo então era essencial - e não o que ele tinha pensado ou imaginado. Era um processo árduo de reconstrução da substância da memória orgânica, longe de qualquer tipo de improvisação. Cieślak iria repetir o processo orgânico, como Grotowski o chama, "a corrente mais interior". Seu trabalho era muito parecido com o que Stanislavsky havia feito durante a fase final do trabalho sobre "o método de atividade física". Quando alguém tinha dificuldades com a ativação da sua memória emocional, Stanislavsky tentava convencê-los a re-encenarem suas antigas atividades. Geralmente, a memória emocional era então desencadeada. Um exemplo de tal cooperação de Stanislavsky com seus atores pode ser encontrado no livro de Toporkow sobre o trabalho em Tartuff - era quase exatamente o mesmo. Grotowski não negou que tal estímulo do processo interno do ator é até agora inatingível para a maioria dos artistas de teatro de todo o mundo, já que para alcançá-lo é preciso muita coragem e tempo. Quem dispõe disso hoje em dia?

Um dos alunos do Departamento de Estudos da Performance da Universidade de Nova York pergunta a Grotowski a respeito da influência de técnicas asiáticas sobre o trabalho dos atores do Teatro Laboratório. Nosso convidado responde que a tradição do Extremo Oriente era mais necessária para ele na área da metafísica do que em métodos de atuação, visto que no último a estrutura da atividade de um ator do Extremo $O$ riente é imposta pela tradição. Mesmo assim, tais atores tendem a ser agraciados com o "ato total". Afinal, atuar 
em tal teatro é quase sempre um serviço sacerdotal. No caso de Cieślak, fomos confrontados com seu grande envolvimento, o talento nato e vocação do ator ("talento, serviço, envolvimento"). Às vezes, enquanto atuava, ele se entregava para algo maior, que existia fora da performance (talvez a Deus?). Ele ia além de seu papel e da estrutura da atuação. Seu papel, no entanto, não havia sido imposto a ele pela tradição. Ele próprio, juntamente com o diretor, foi o seu autor. Ao criar o sistema de trabalho para o ator do Teatro Laboratório, eles não trouxeram técnicas do Extremo Oriente, mas tentaram criar algo original, suprindo suas próprias necessidades.

Robert Findlay perguntou sobre o aspecto político do funcionamento e da atividade criativa do Teatro Laboratório. O problema subjacente desta questão era a forma como a companhia tinha se colocado na cultura política do regime comunista. Grotowski respondeu que o sistema de poder na Polônia de 1959-1968 era fraco, mas agressivo. Em algum momento foi necessário escolher uma estratégia de sobrevivência e luta contra ele. Um anúncio referindo-se aos aspectos políticos das suas produções teatrais teria sido um gesto muito honesto e, ao mesmo tempo, muito espetacular. $E$ esse mesmo gesto teria posto um fim à existência de seu teatro. Eles eram simplesmente muito fracos para lutar abertamente contra a fraca tirania. Por outro lado, não queriam ser associados com a tendência católica de oposição ao comunismo, já que também eram contra o catolicismo polonês. É preciso dizer, no entanto, que a influência do Teatro Laboratório nas pessoas (não só no público) tinha um caráter político. A própria existência do Teatro e sua persistência era um ataque explícito à ideologia oficial de criação de arte, e, ao mesmo tempo, um ataque contra a intolerância católica. Sobreviver em tais condições era muito difícil, visto que na verdade todas as estruturas oficiais existentes na República Popular da Polônia uniram-se na luta contra o fenômeno do Teatro Laboratório. Muitas pessoas acharam que a sua própria existência era um ataque a essas estruturas. Muito frequentemente, pessoas completamente desconhecidas Ihes davam um apoio, sempre bem-vindo. 
Era então a hora de minha pergunta. Perguntei a Grotowski como ele havia conseguido desenvolver uma atividade tão séria em um país tão fútil, no qual tudo tinha sido "insuportavelmente leve", e que insinuava seriedade; a verdadeira batalha com a vida havia invariavelmente se tornado um objeto de desprezo e escárnio. Ele respondeu que, de fato, desde o início do seu trabalho um riso zombeteiro havia acompanhado a ele e a seus colegas do Teatro Laboratório. Eles nunca se preocuparam com isso e fizeram seu trabalho. Ele prontamente acrescentou que as pessoas que levavam a si mesmas, suas vidas e seus trabalhos a sério, muitas vezes os animavam e sempre foram seus aliados. Então ele nos contou sobre as relações dele e de seu grupo com várias pessoas entre os aliados (a partir do contexto, deduzi que se referia a Irena e Tadeusz Byrski e Jan Kreczmar).

A pergunta seguinte referia-se ao método de trabalho em todo o roteiro de $O$ Príncipe Constante - até que ponto era uma criação do diretor ou dos atores. Grotowski respondeu que não havia regras, praticamente cada cena tinha sido única. Algumas delas eram mais o trabalho do diretor, algumas pertenciam ao grupo. A regra era a dialética do processo criativo. Por exemplo, Grotowski deu a ideia de procissão-com-marchas, e os atores a desenvolveram. Neste ponto, as sugestões deles tornaram-se suas ideias. É difícil determinar a autoria com precisão.

Alguém perguntou o que estava por trás da ideia de uma forma tão singular do espaço teatral. A resposta de Grotowski corresponde ao que pode ser lido em diversos estudos: O Príncipe Constante do Teatro Laboratório foi concebido como uma exemplificação em primeira mão da força bruta usada contra um indivíduo livre pela comunidade que utiliza a violência institucionalizada. Desta forma, a ideia de formar o espaço surgiu naturalmente: deveria ser o teatro de operação cirúrgica, o teatro de corrida, no qual o público pudesse rastrear os atos de crueldade e sofrimento humano. Além disso, Grotowski disse que a ideia das cabeças dos espectadores saindo por cima da paliçada, seguindo a ação, havia sido concebida pelos autores para criar um elemento crucial do cenário teatral. 
Alguém perguntou como Grotowski e seus atores tiveram a ideia de que o piso poderia se tornar um instrumento musical. A resposta foi de que a idéia thes passou pela cabeça quando estavam trabalhando intensamente com os ressonadores no corpo humano. Naquela época, eles estavam "conversando" com o chão durante os exercícios. Esses momentos da performance, nas quais os atores usam o chão como um instrumento, foram trabalhados durante os ensaios finais. Grotowski temia que ensaios iniciais em modo "técnico" puro bloqueassem o processo interno de Cieślak.

A pergunta seguinte referia-se ao público polonês do Teatro Laboratório - até que ponto ele tinha mudado quando o Teatro obteve sucesso no Exterior e tornouse famoso. Grotowski me surpreendeu muito com sua resposta, que definitivamente superou (e muito bem) a questão. Ele nos disse que a Polônia precisava de um grupo como o deles. Era um grupo que lançava um desafio a todas as instituições e autoridades. Os membros do Teatro Laboratório eram pessoas fortes e ousadas, os Vikings do palco. Era um tipo específico de "gangue". Eles deram o seu melhor, viveram intensamente, "foram até o fundo", como dizem. A prova disto é a morte prematura de muitos deles. Eles jogavam seu peso, trabalhavam feito doidos, se divertiam, bebiam, fumavam... Para entrar no grupo, era necessário ter muita força. No entanto, o critério principal era sempre a capacidade de dar duro.

Em se tratando da audiência, houve altos e baixos. No início, eles se apresentavam para um punhado de pessoas ou apenas um espectador. Mais tarde, tamanha era a multidão que se dirigia a eles que era impossível acomodá-los todos na plateia. Desde o início, Grotowski era da opinião de que não deveriam mudar seus modos, que não deveria ser sua prioridade receber grandes multidões em suas apresentações. Ele estava totalmente convencido de que se continuassem a se desenvolver como deveriam, as enormes multidões os seguiriam. E foi o que aconteceu. Nunca, em suas declarações, artigos, manifestos, ele usou o termo "o público", pois ele odiava um espectador não-definido, nascido de uma abstração estática. Eles desejavam ter pessoas, e não uma multidão em seu Teatro 
Laboratório. A presença de uma multidão em uma performance definitivamente reduz o nível da sua recepção.

Durante os primeiros anos de atividade, uma pergunta invariavelmente acompanhava seu trabalho: se alguém, diante de um número tão pequeno de espectadores, finalmente colocaria um fim a esse teatro, ou os permitiria existir por um pouco mais de tempo. Pois eles eram apenas um pequeno teatro experimental, que trabalhava em suas performances por um longo tempo, e depois se apresentava raramente a um público muito escasso.

A questão que se seguiu era relacionada às regras do processo criativo do ator, as quais Grotowski havia inventado durante seu trabalho com Cieślak. Alguém perguntou como tais relações entre os sentimentos do ator e "memória do corpo" deveriam ser desenvolvidas durante a atuação, de acordo com esta experiência criativa. É estritamente necessário apoiar a memória emocional com atividades físicas? Grotowski sorriu: é assim que inúmeros mal-entendidos ocorrem. É preciso estar ciente de que as emoções de uma pessoa são independentes da sua vontade, é por isso que elas precisam ser evocadas por meio de atividades físicas. Um ator deve estar muito vigilante e aberto a esta possibilidade de processo criativo direto, que pode ocorrer a qualquer momento, uma espécie de encontro com suas próprias emoções vivas. Se este processo não for genuíno, ele só dá a luz a atuações clichê. Isso também é necessário para manter a qualidade da memória emocional. Algumas pessoas usam isso para procurar por alguma recordação comum, com origem na monotonia da vida cotidiana. No entanto, no processo criativo, o que realmente importa é alcançar a memória emocional mais profunda, como a que dá força aos livros de Dostoievski.

A próxima questão: como ele conseguiu manter sua companhia de teatro por um tempo tão longo? Não, ele não acha que foi um tempo tão longo. Na verdade, foram apenas 20 anos, pois o primeiro ano do Teatro de 13 Fileiras só deve ser associado a jogos teatrais e, em 1982, o grupo de fato deixou de existir. Um fator 
significativo que contribuiu para a longa existência do grupo é definitivamente a escolha dos atores em uma performance em particular e escalá-los em papéis específicos. Tais decisões devem ser perspicazes, e devem levar em conta a capacidade do ator para se desenvolver.

Alguém pede a Grotowski uma descrição mais específica de sua atitude em relação ao "método de ação física" de Stanislavsky. Grotowski disse que ele simplesmente iniciou seu trabalho na área da "ação física" a partir de onde Stanislavsky tinha parado. O mestre russo falou do "método de ação física", mas sempre quis se referir ao desencadear do processo espiritual interior de um ator. As atividades físicas dos atores deveriam tomar a forma de notas musicais em uma performance, deveriam marcar a área para ativar fragmentos sucessivos do processo. Forçar um ator a falar sobre suas emoções pode matá-lo. Atores devem tomar medidas para alcançar a fonte do processo interior autêntico. A conversa mencionada acima entre Grotowski e Cieślak no restaurante da estação de trem foi muito cautelosa. Grotowski não queria afugentar sentimentos genuínos de seu companheiro. E não os afugentou. Portanto, o processo crucial iniciou-se somente quando Cieślak entrou em ação.

A questão seguinte referia-se à abordagem de Grotowski para as tendências em ideias e práticas teatrais que não as que ele tinha criado. A resposta foi explícita: ele era capaz de aceitar qualquer proposta genuína. Como exemplo, ele citou a sua amizade com Helena Weigel, a atriz excepcional do Conjunto Berliner, esposa de Bertolt Brecht. Quando se conheceram, Brecht já havia falecido, mas existiam seus alunos, que lutavam ferozmente contra "os de Grotowski". No entanto, ele imediatamente teve um excelente entendimento com Helena Weigel. A amizade durou até a morte dela, uma vez que ambos sempre se sentiam revigorados pela curiosidade por coisas novas, interessantes, originais, e confiavelmente concebidas.

E agora, a hora para a minha pergunta sobre "irmãos de armas". É assim que Grotowski chama as pessoas que fazem referência a ele como seu mestre, mas 
seguem seus caminhos criativos originais. Também estou interessado em saber como ele vê o problema atual de imitações impensadas e referência sem sentido à sua autoridade por fraudes descaradas. O que aconteceu foi que ele ficou mais distante do que antes. E agora ele usa o termo "irmãos de armas" para pessoas que se relacionam com ele honestamente. Livrar-se de "estudantes" perturbadores é o mesmo que se livrar dos estereótipos que outras pessoas fazem dele. Mesmo assim, ele é influenciado não só por si próprio, mas também pelos estereótipos dessas pessoas.

Alguém perguntou a Grotowski, quando ele sentiu que O Príncipe Constante poderia ser apresentado ao público. Grotowski respondeu que isso aconteceu quando tudo na apresentação já havia sido "resolvido". Nesse momento, espontaneamente, sem premeditação, a necessidade de um novo choque emergiu a presença do espectador. Se nesse ponto isso ainda faltasse, reencenar a apresentação durante ensaios subsequentes poderia ser uma ameaça de uma repetição mecânica do que já havia sido aprendido de cor.

Grotowski prontamente acrescentou que a decisão de interromper a apresentação também surgiu repentina e inesperadamente, quando ela já havia alcançado grande sucesso, e quando ainda era possível representá-la por muitos anos. Por exemplo, um dia, durante a sua estadia em Berlim, e após um encontro com Helena Weigel, ele ouviu (não assistiu, mas ouviu) O Príncipe Constante de trás do altar de uma igreja onde estavam se apresentando. Foi então que ele percebeu que o desempenho estava excelente, preciso, brilhantemente executado, mas não havia mais risco algum nele. Estava morto. Pouco depois, pararam de encená-lo. Do seu ponto de vista, a estreia não era o objetivo, bem como não era seu objetivo tentar atingir uma "exploração" de longa duração do espetáculo. Eles pretendiam "penetrar" na performance ao atuá-la. Do seu ponto de vista, cada apresentação deveria ser associada ao risco, ao inesperado, ao que continuava a surpreendê-los. Quando sua performance não apresentava mais isso, era hora de encerrá-la. 
A seguir, alguém perguntou sobre como a "edição emocional" do diretor havia sido recebido pelo público no Exterior. A recepção havia sido considerada durante 0 trabalho de edição? Grotowski simplesmente respondeu que não, uma vez que todas as apresentações do Teatro Laboratório foram concebidas para um público polonês. No entanto, houve casos em que O Príncipe Constante conseguiu revelar e manifestar ricas reservas de emoções de espectadores estrangeiros, tocando em algumas tradições locais, desconhecidas anteriormente pelos autores, mas perto de sua mensagem e da substância da apresentação. Foi muito animadamente recebida, por exemplo, pelas pessoas comuns em Teerã. Para elas, era uma história sobre mártires xiitas (o Teatro Laboratório se apresentou lá com O Príncipe Constante durante o regime do Xá, antes da revolução islâmica). Também no México, a recepção dessa apresentação foi ambientada na tradição indígena e cristã do martírio. Naquele país, as histórias da paixão estão profundamente enraizadas na tradição popular pré-colombiana. Um fenômeno interessante ocorria quando o público aplaudia ao final da performance; era certo que algo tinha dado errado, que atores e plateia não haviam se unido. A título de contraste, quando algo significativo acontecia entre os atores e os espectadores, eventos se desenvolviam como aconteceu na Cidade do México: após o término do espetáculo a audiência ficou sentada por 10 minutos em silêncio absoluto. Uma senhora idosa então chorou, depois mais alguns minutos de silêncio se seguiram, até que finalmente as pessoas começaram a sair, devagar, sem palavras. Para Grotowski, o aplauso após essa apresentação significava que as pessoas a tratavam como uma mercadoria, e não como um fato. Esta regra, no entanto, não se aplica a todos os espetáculos de teatro. Mesmo performances excelentes, profundas e tocantes podem ser agraciadas de tal forma pelo público, e não há nada de errado nisso. Grotowski, por exemplo, não tinha dúvidas de que aplausos eram devidos após a Mãe Coragem de Brecht, com o enorme, crucial papel de Helena Weigel.

Robert Findlay perguntou então a Grotowski por que os atores do Teatro Laboratório haviam trabalhado por tanto tempo no Apocalypsis cum Figuris. Grotowski respondeu que por três vezes lhe parecia que a apresentação estava 
pronta para enfrentar uma audiência, mas, ao refletir melhor, ele adiou a estreia. Era difícil para os atores se libertarem do sucesso e dos hábitos adquiridos em outras apresentações. Grotowski levantou então vários pontos muito importantes sobre estudos individuais, que tinham ajudado alguns atores a descobrirem as qualidades essenciais de seus personagens. Por exemplo, durante os estudos de textos com provérbios bíblicos, Zygmunt Molik começou a recitá-los como se um agente da polícia secreta estivesse contando piadas sobre política. Desta forma, ele foi colocado na trilha de "seu" Judas. Elisabeth Albahaca escolheu para si o texto mais ousado de amor, e Cieślak leu os Evangelhos através de seu amado Eliot.

Findlay perguntou como Antoni Jaholkowski tinha achado o texto do Grande Inquisidor. Grotowski respondeu que Jaholkowski tinha trabalhado os Evangelhos muito conscientemente, como de costume, e em algum momento todos os membros do grupo notaram que, sob a influência deste trabalho, ele tinha mudado muito. Finalmente, alguém compreendeu no que esta transformação consistia: Jaholkowski estava se transformando em um padre ortodoxo durante os ensaios. A partir do personagem do padre, eles chegaram ao personagem do Grande Inquisidor. Assim, eles tocaram em um arquétipo muito significativo. A blasfêmia final do Inquisidor deveria ser muito pessoal, resultante de uma experiência profunda. De outra forma, teria apenas se tornado uma ofensa contra a religião.

Neste momento, Grotowski anunciou que era hora de acabar nosso encontro; ele pegou suas coisas da mesa e se levantou. De acordo com as instruções que haviam sido passadas, permanecemos sentados imóveis em nossos lugares. Nosso convidado vestiu o casaco, se voltou para a sala, acenou calorosamente e saiu. Era evidente que ele estava cansado. Ele nos deu o seu melhor, tanto quando podia.

Ainda estávamos sentados em nossas poltronas, algumas pessoas foram mais ou menos discretas ao desligar seus gravadores. (Obviamente, a gravação do encontro com Grotowski não tinha sido permitida, mas essa restrição tinha sido, em geral, violada.) A sala gradualmente e sem pressa começou a ficar deserta. Era 
quase meia-noite, e no dia seguinte deveríamos retornar com cabeças limpas para as últimas aulas e debates do nosso seminário sobre o "período teatral" de Jerzy Grotowski. 